\title{
Interfacial Resistance Due to Thin Films of Alcohols and Its Effect on the Rate of Evaporation of Water
}

\section{LALIT H. UDANI and KENNETH F. GORDON}

University of Michigan, Ann Arbor, Michigan

Measurements were obtained of the interfacial resistance due to thin films of straightchain higher alcohols and their effect on the evaporation of water. This was done by passing preheated dry air at a constant rate over water in a beaker. Unlike previous studies both phases were stirred. Four alcohols, dodecyl, myristyl, cetyl, and stearyl, were studied. A large reduction in evaporation was observed when $0.00025 \mathrm{gm}$. of cetyl alcohol was added to 1 liter of water with gas-liquid interfacial area of $0.2015 \mathrm{sq}$. $\mathrm{ft}$. A much higher amount of stearyl alcohol, $0.0006 \mathrm{~g}$., was needed for commensurate effect. Resistance due to films of dodecyl and myristyl alcohols was neglibible. For the most part cetyl alcohol is the most effective of those tested. Plots are given of the pseudo mass transfer coefflcients and interfacial resistances as a function of the amount of the various alcohols.

When placed on a water surface an insoluble substance will spread on the surface if the energy of adhesion between the molecules of the substance and water is greater than that between the molecules of the substance itself. Long-chain fatty acids and alcohols fulfill this condition and form a layer on water surface. This layer can be regarded as the solution in water of the hydrophilic end group of the molecule, with the hydrophobic end tending towards the gas phase. Such a film is known to retard the evaporation of a liquid into both stagnant and flowing air streams. A brief review of the past work falls naturally into three sections, each with a quiet unstirred water phase.

\section{QUIET AIR PHASE AT REDUCED PRESSURE}

Rideal (23) used an evacuated inverted $U$ tube with one leg containing water at either $25^{\circ}$ or $35^{\circ} \mathrm{C}$. and the other at $0^{\circ} \mathrm{C}$. Considerable reduction in evaporation was observed with films of stearic, lauric, and oleic acids. Sebba and Sutin (27) measured the rate of evaporation of water into an evacuated chamber as a function of the surface pressure of the film of stearic acid achieving up to $80 \%$ reduction but found no effect for cholesterol.

\section{QUIET AIR PHASE AT ATMOSPHERIC PRESSURE}

Powell (21) has studied the effect of oil films up to $2.5 \mathrm{~cm}$. thickness. Langmuir and Schaefer (1/4), Archer and La Mer (2), and Rosano and La Mer (24) have also reported reductions in evaporation. The latter used nine substances, alcohols, acids, and esters all spread as monomolecular layers. Arachidic acid gave the highest resistance, twice that of cetyl alcohol. They examined surface pressure-area isotherms, surface viscosity, and the surface pressure-evaporation resistance relationship and concluded that incompressible films gave the highest resistance. Mansfield (2Q) found that the resistance of cetyl alcohol changed little with time, while that of both myristyl alcohol and cholesterol dropped to one quarter of their initial values in 300 min. The resistance of cetyl alcohol was a strong function of temperature, remaining constant from $20^{\circ}$ to $30^{\circ} \mathrm{C}$, declining to one third of the $30^{\circ} \mathrm{C}$. values at $40^{\circ} \mathrm{C}$., and to one quarter of the $30^{\circ} \mathrm{C}$. value at $50^{\circ} \mathrm{C}$. Field results are included. McArthur and Durham (17) give values of the film resistance of various combinations of alcohols.

\section{FLOWING AIR AT ATMOSPHERIC PRESSURE INCLUDING RESERVOIRS}

Although Hedestrand (12) has reported no effect due to films of palmitic and

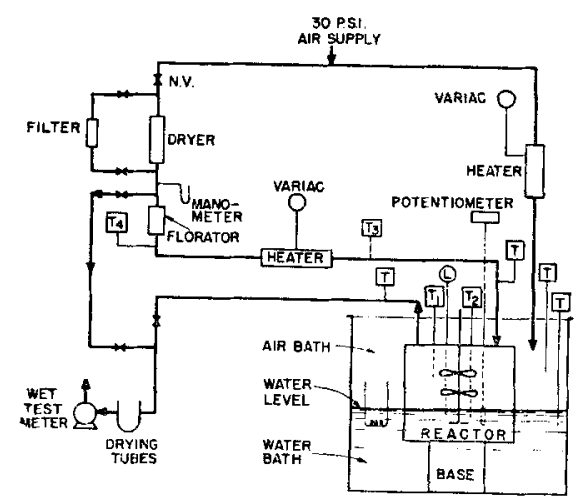

Fig. 1. Flow sheet, $\mathrm{L}=$ level indicator, $\mathbf{T}=$ thermometer; N.V. $\approx$ needle valve. oleic acid in the evaporation of water in a dish, others have found a definite decrease. Langmuir and Iangmuir (19) observed appreciable reductions only with films of cetyl alcohol and confirmed Hedestrand; however they did observe a reduction in rate of evaporation of ether from an aqueous ether solution with different films. Docking and coworkers (4) using paraffin oil films 1 to $2 \mu$ thick observed a reduction of up to $60 \%$ in evaporation from open Petri dishes and up to $99 \%$ with neutral oil of retort tar. Sebba and Briscoe (25) found large reductions due to unimolecular films of various alcohols and acids. Powell (21) working with Petri dishes in a wind tunnel reports large reductions in evaporation of water due to thin multimolecular oil films. Recently Mysels (20) published a short note on the resistance of cetyl alcohol to evaporation from a dish. McArthur and Durham (17) have obtained up to $67 \%$ less evaporation using cetyl alcohol in various combinations with other alcohols in tests employ. ing Petri dishes. Baranaev and his associates (3, 28, 29, 30) studying systems with air or hydrogen bubbling through liquid and with air flowing over the liquid surface observed reductions in the rate of evaporation of water and other compounds from aqueous solutions with cetyl alcohol and other substances as films.

Applications are found in the retardation of evaporation from lakes and reservoirs such as reported by Moulton (19), Grundy (10), and Mansfield (15, 16, 22) who found about $75 \%$ reduction in evaporation with cetyl alcohol in field tests. Groth $(9)$ briefly mentions tho suppression of evaporation from snow by alcohol films obtaining up to $50 \%$ reduction. Economics have been discussed by Dressler and Johanson (5). The proceedings of a conference on rescrvoir evaporation control has been published (2Q).

A review of Russian work should include that of Glazov $(7,8)$ who reports 


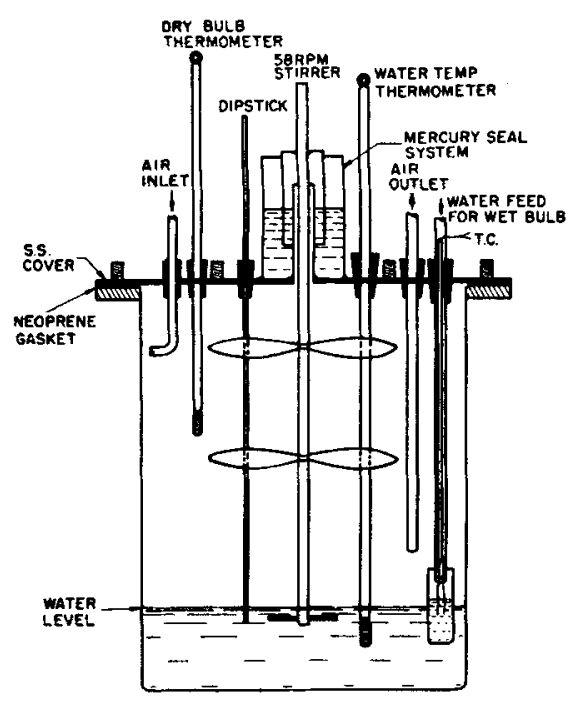

Fig. 2. Vessel.

on various alcohols which are more effective than acids or amines in reducing evaporation. Where possible, representative data of various authors have been converted to resistances in the same units as used in the present work and are given in Table 1. The conversions are obtained with the assumption that the gas-liquid interface is at the same temperature as the bulk of water. Because the mixing in the water is unknown interfacial conditions cannot be accurately estimated. The partialpressure driving force at the interface is taken to be that corresponding to the assumed interfacial temperature. It may be noted that the magnitude of the coefficients and resistances varies considerably for different authors. This is due to the great differences in the equipment and procedures used. The error introduced by the assumption that the interfacial temperature is the same as the bulk water temperature may be appreciable. If the interfacial temperature is taken to be the same as the wetbulb temperature corresponding to the temperature of the entering dry air, the driving force is reduced by a factor of about $21 \%$ which in turn would increase $K_{O G}$ and reduce the resistance correspondingly. Even for the case of no surfactant the interfacial conditions cannot be accurately estimated for the runs reported in the literature. There the bulk water and interfacial temperatures are different. Thus some assumption must be made to obtain an estimate of the magnitude of $K_{O G}$ and hence of the resistance. However these estimates of mass transfer coefficients and resistances will be useful for comparison with our experimental results. It will be seen that in the present work the mass transfer coefficient for pure water without surfactant is accurately known, for the bulk water and wet-bulb temperatures are the same.

\section{OBJECTIVE}

The present work was undertaken to obtain laboratory measurements of interfacial film resistance due to alcohol films in an apparatus resembling commercial chemical equipment in that both phases are agitated. The reduction of the rate of evaporation of water in the presence of various amounts of straight-chain higher alcohols was measured. The alcohols used were dodecyl alcohol, myristyl alcohol, cetyl alcohol, and stearyl alcohol. It was desired to determine the amount needed to obtain a significant reduction in the rate of evaporation.

\section{APPARATUS}

The flow sheet of the process is presented in Figure 1. Air at $0.74 \mathrm{cu}$. ft. $/ \mathrm{min}$. from a $30 \mathrm{lb} . / \mathrm{sq}$. in. line was dried by passing through Drierite, then through a tubular furnace, and on to the vessel containing the evaporating water. The constant air flow was measured by a Florator with a mercury manometer to give the air pressure. The unbaffled vessel, shown in Figure 2 , was a $3 \frac{1}{2}$ liter stainless steel beaker fitted with an air tight stainless steel cover with a neoprene gasket. A motor and reducing gear gave a constant stirrer speed of $58 \mathrm{rev} . / \mathrm{min}$. One liter of distilled water was initially put in the beaker with a few cubic centimeters makeup periodically added to maintain the level with negligible variation. The surface area of the water was 0.2015 sq. ft., as determined by the cross section of the vessel. A system consisting of a glass water reservoir and copper constantan thermocouple, with a wick which was well exposed to the flowing air, was used to measure the wet-bulb temperature of the air. The air left the vessel through a tube placed where it would give the maximum concentration of water in the air, namely 2 in. above the surface. Other positions apparently gave greater bypassing.

The stirrer consisted of a mercury sealed $1 / 4$-in. shaft extending to within $3 / 4$ in. of the beaker floor with a single $1 / 8$-in. diameter rod of total length $2 \frac{1}{4}$ in. centered at right angles through the vertical shaft and approximately $3 / 4$ in. below the water surface which was $2 \frac{1}{16}$ in. above the beaker floor. In the gas phase were two 3-in. diameter four blade propellers, one $1 \frac{1}{4}$ in. and the other $43 / 4$ in. above the water surface, as well as a 3 -in. diameter two blade propeller $3 \frac{3}{4}$ in. above the interface. Like the beaker and cover the stirrer was wholly of stainless steel. During runs both phases were turbulent; yet the interface was relatively smooth with surface ripples but no waves.

A glass tube reaching into the water phase was used to indicate the pressure in the vessel by the height of water in the tube. Water in the vessel was maintained at $25^{\circ} \mathrm{C}$. by immersing the vessel in a water bath up to the level of water inside the vessel. The water-bath temperature was controlled by a system of a cooling coil and a thermostat controlled knife heater, while the rest of the vessel was surrounded by an air bath which was maintained at the same temperature as the air leaving the vessel. The air fed to the air bath was preheated in a Variac controlled tubular heater as was the air to the vessel. To reduce the heat transfer between the air and water baths a partition of a thin copper plate and a dry plywood sheet separated them. Increments of measured amounts of alcohol were added to give a cumulative effect. When the steady state had been achieved, a $0.50 \mathrm{cu}$. ft. sample of the exit air from the vessel was drawn through a series of drying tubes and then to a wet test meter. In order to avoid a build-up of pressure in the vessel during sampling a bypass was used to let most of the air to the atmosphere. To maintain constant pressure in the vessel during a run air was continuously bled through a dummy sample train. During actual sampling the air was switehed from the dummy to the real sample train. This precaution eliminated fluctuations in the observed wet-bulb temperature during tests before the runs. The humidity of the dried inlet air was determined by drawing a $1 \mathrm{cu}$. ft. sample through a series of drying tubes.

With pure water a bulk gas temperature of $49.3^{\circ} \mathrm{C}$. and a bulk liquid temperature of $25^{\circ} \mathrm{C}$. allowed a wet bulb of $25 \pm 0.2^{\circ} \mathrm{C}$. to be maintained, showing that control of bulk temperatures gave reproducable operating conditions. This obviated diffculties with wet-bulb readings on alcohol contaminated systems. Since the wet-bulb system was not used during a run, no correction was required for evaporation from the wick.

Once added, alcohols adhered to cquipment parts so tenaciously that unless extra precautions to clean the equipment were taken, the subsequent results would be vitiated. Since fatty alcohols are soluble in ether, the equipment was first thoronghly cleaned with ether. The reactor was then flled with $2 \%$ sodium hydroxide solution and heated to boiling for $15 \mathrm{~min}$. After the alkali had been washed away with water, the vessel was filled with water and heated to boiling. Each time the cover was placed in position the stirrer, etc. were given this treatment. To obtain consistent readings it was also found necessary to let the equipment run for 3 to $4 \mathrm{hr}$. after every addition of alcohol before making measurements. After this initial period

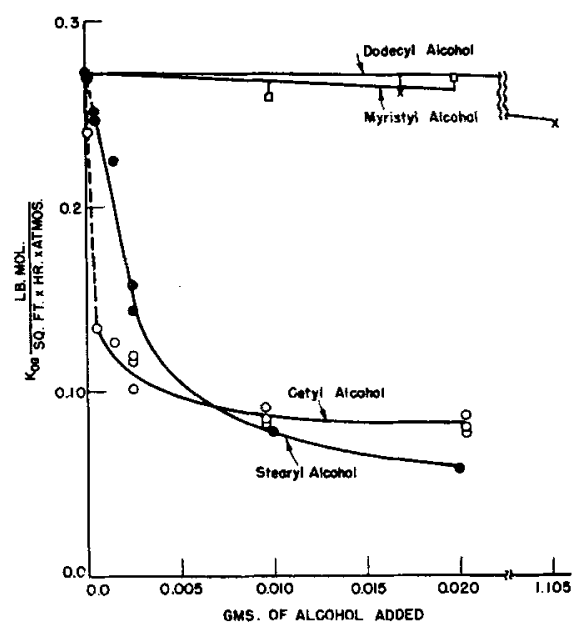

Fig. 3. Effect of alchol on mass transfer coefficient. 
Table 1. Summary of Literature Data on Interfacial ResistanceWATER UNSTIRRED

\begin{tabular}{|c|c|c|c|c|}
\hline \multirow[b]{2}{*}{ Source } & \multirow[b]{2}{*}{ Surfactant } & \multirow{2}{*}{$\begin{array}{c}\text { Surface } \\
\text { pressure, } \\
\text { dynes/cm. }\end{array}$} & $\begin{array}{l}\text { (Pseudo) } K_{O G} \\
\text { lb. mole }\end{array}$ & \multirow{2}{*}{$\frac{\begin{array}{c}R_{i} \\
(\mathrm{hr} .)(\mathrm{sq} . \mathrm{ft} .)(\mathrm{atm} .)\end{array}}{\text { lb. mole }}$} \\
\hline & & & $($ hr. $)($ sq. ft. $)($ atm. $)$ & \\
\hline & None & $(0)$ & & $(0)$ \\
\hline Archer and & $\mathrm{C}_{19-\text { acid }}$ in benzene & 3 & & 0.60 \\
\hline $\operatorname{La} \operatorname{Mer}(\mathscr{L})$ & & 12 & & 0.80 \\
\hline Air velocity & & 16 & & 1.66 \\
\hline \multirow{2}{*}{$0 \mathrm{ft} . / \mathrm{sec}$} & & 23 & & 3.65 \\
\hline & & 26 & & 5.15 \\
\hline Both phases & & 29.5 & & 6.64 \\
\hline \multirow[t]{5}{*}{$25^{\circ} \mathrm{C}$} & $\mathrm{C}_{18 \text {-acid in }}$ & 8 & & 7.98 \\
\hline & Petro ether & 13 & & 9.26 \\
\hline & & 18 & & 10.62 \\
\hline & & 25 & & 11.95 \\
\hline & & 29 & & 13.28 \\
\hline Rosano and & Ethyl palmitate & 22 & & 0 \\
\hline La Mer (24) & Ethyl linoleate & 25 & & 0 \\
\hline Air velocity & Ethyl elaidate & 18 & & 0 \\
\hline \multirow[t]{7}{*}{$0 \mathrm{ft} . / \mathrm{sec}$} & Ethyl stearate & 31 & & 13.6 \\
\hline & Arachidic acid & $4-32$ & & 17.3 \\
\hline & Stearic acid & $13-24$ & & 6.0 \\
\hline & 1-Octadecanal & 42 & & 1.0 \\
\hline & Cetyl alcohol & 44 & & 8.6 \\
\hline & $1,1,13$-Trihydroper- & & & \\
\hline & $\begin{array}{l}\text { fluorotridecyl } \\
\text { alcohol }\end{array}$ & $19-37$ & & 5.6 \\
\hline \multicolumn{5}{|c|}{ Curves of data from the above points to the origin are given (24) } \\
\hline Mansfield (22) & Cetyl alcohol & & & 11 . \\
\hline Air velocity & Cholesterol & & & 5. \\
\hline $0 \mathrm{ft} . / \mathrm{sec}$. & Tetradecanol & & & 9 \\
\hline Bulk air $25^{\circ} \mathrm{C}$. & $\begin{array}{l}\text { Values as a function } \\
\text { and as a function of }\end{array}$ & $\begin{array}{l}\text { of temperat } \\
\text { time for all }\end{array}$ & $\begin{array}{l}\text { ure for cetyl alcohol } \\
\text { three are given }(22)\end{array}$ & \\
\hline McArthur and & Cetyl and other & & & $2.7-8.2$ \\
\hline Durham $(17)$ & alcohols & & & \\
\hline \multicolumn{5}{|l|}{$0 \mathrm{ft} . / \mathrm{sec}$. } \\
\hline \multirow[t]{2}{*}{ Rideal (23) } & None & & 16.9 & 0 \\
\hline & None & & 12.2 & 0 \\
\hline Air velocity & Lauric acid & & 9.76 & 0.0043 \\
\hline $0 \mathrm{ft} . / \mathrm{sec}$. & & & 8.23 & 0.0039 \\
\hline \multirow{4}{*}{$\begin{array}{l}\text { Water } \\
\text { Alternately } \\
25^{\circ}, 35^{\circ} \mathrm{C} \text {. } \\
\text { Vacuum }\end{array}$} & Oleic neid & & 8.23 & 0.0039 \\
\hline & & & 6.05 & 0.0083 \\
\hline & Stearic acid & & 12.2 & 0.0023 \\
\hline & $"$ & & 9.65 & 0.0022 \\
\hline Langmuir and & None & & 0.0298 & 0 \\
\hline Langmuir (19) & Oleic acid & & 0.00338 & 262 \\
\hline Ethyl ether & & & & \\
\hline from water & Stearic acid & & 0.00515 & 160 \\
\hline \multirow{3}{*}{$\begin{array}{c}\text { Air velocity } \\
0 \mathrm{ft} . / \mathrm{sec} .\end{array}$} & Cetyl palmitate & & 0.00465 & 182 \\
\hline & Cetyl alcohol & & 0.0032 & 278 \\
\hline & Myricyl alcohol & & 0.00438 & 194 \\
\hline \multirow[t]{5}{*}{$2.0 \mathrm{ft} . / \mathrm{sec}}$. & None & & 0.071 & 0 \\
\hline & Oleic acid & & 0.00375 & 253 \\
\hline & Cetyl palmitate & & 0.00450 & 208 \\
\hline & Stearic acid & & 0.00455 & 206 \\
\hline & Cetyl acid & & 0.00342 & 278 \\
\hline $5.0 \mathrm{ft} . / \mathrm{sec}$. & None & & 0.0808 & 0 \\
\hline & Oleic acid & & 0.00375 & 255 \\
\hline & Cetyl palmitate & & 0.00495 & 190 \\
\hline & Stearic acid & & 0.00561 & 166 \\
\hline & Cetyl alcohol & & 0.00425 & 228 \\
\hline Water from & None & & 0.0309 & 0 \\
\hline water & Cetyl alcohol & & 0.0255 & 6.8 \\
\hline$v=0 \mathrm{ft} . / \mathrm{sec}$ & & & & \\
\hline$v=5.8 \mathrm{ft} . / \mathrm{sec}$. & None & & 0.197 & 0 \\
\hline & Cetyl alchol & & 0.104 & 4.55 \\
\hline Mysels (20) & None & & 0.825 & 0 \\
\hline Air velocity & Cetyl alcohol & & & 6.44 \\
\hline $\begin{array}{l}8.8 \mathrm{ft} . / \mathrm{sec} \\
26.4 \mathrm{ft} . / \mathrm{sec} .\end{array}$ & None & & 1482 & 0 \\
\hline & Cetyl alcohol & & 1.482 & 7.08 \\
\hline
\end{tabular}

where the resistance increased, possibly due to solution of the added alcohol, no further change was observed during the experiment which sometimes was extended over a 24-hr. period. Sebba and Briscoe (26) observed that aging reduced the resistance of a $n$-docosanol film, while Mansfield (22) found no effect for cetyl alcohol.

The surface pressure was obtained from the difference of the surface tension of pure water and that measured in the apparatus by a ring tensiometer. It varied from 0 to 51 dynes $/ \mathrm{cm}$.

\section{RESULTS}

When an alcohol is added to water the actual saturation temperature at the interface is expected to be higher owing to decreased cooling with the lowered rate of evaporation. This higher interfacial temperature cannot be satisfactorily measured by the usual techniques. As the decrease of evaporation rates with alcohols was the main interest, the results are presented to show the reduction. This was done by plotting the pseudo mass transfer coefficient for the runs with alcohols. The pseudo coefficient was calculated from the measured rate of evaporation with the difference between the vapor pressure of pure water at $25^{\circ} \mathrm{C}$. and the measured partial pressure of water in the exit stream which was taken to be that of the bulk gas used as the driving force. It is to be noted that when no alcohol is present the pseudo coefficient becomes the usual coefficient.

Figure 3 is a plot of the pseudo mass transfer coefficient against the amount of alcohol added. Figure 4 shows the apparent interfacial resistance for various alcohols against the amount of alcohols added. The interfacial resistance was determined from

$$
R_{i}=\frac{1}{k_{f}}=\frac{1}{K_{O G}}-\frac{1}{k_{g}}
$$

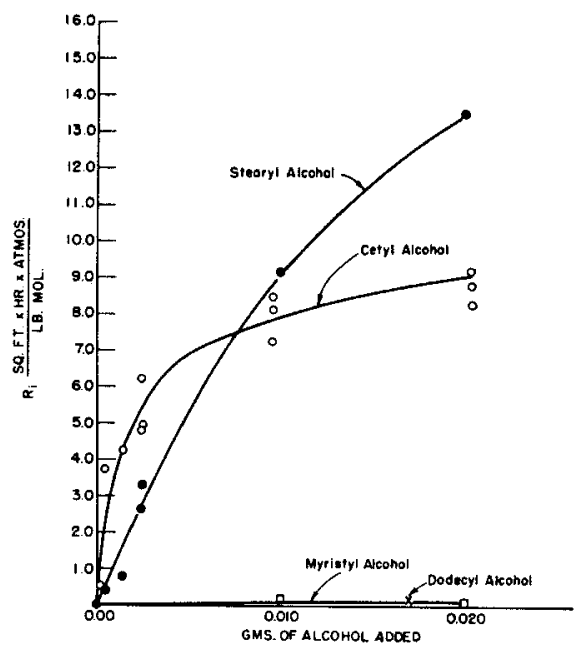

Fig. 4. Apparent interfacial resistance as a function of alcahol added. 
From Figure 4 it is clear that the interfacial film resistance of cetyl alcohol increases rapidly on a slight addition of the compound as compared with stearyl alcohol. In the case of stearyl alcohol resistance increases gradually but is greater than that of cetyl alcohol when a larger amount of alcohol is added. The resistance due to dodecyl alcohol and myristyl alcohol appears to be negligible.

When one assumes that the effective cross section of an alcohol molecule is $20.5 \mathrm{sq} \AA$. (1), the amounts of fatty alcohols required to form a monomolecular layer on the air-water surface available in the vessel, 0.2015 sq. ft., are for cetyl alcohol, $0.000037 \mathrm{g.}$, and for stearyl alcohol, $0.000041 \mathrm{~g}$. From Figure 3 it is seen that in the present work a much larger amount of alcohol than that required for a monomolecular layer is necessary to cause a significant reduction in the rate of evaporation. It was considered that since water wetted the stainless steel beaker wall, the surfactant would creep along the walls of the container. Milbauer (18) has observed the effect of various treatments, like coating, etching, and tinning the surface of the vessel, on the rate of evaporation of water in the presence of films. Such treatment affected the wettability of walls with water and hence the film formation. Hence it is believed that the formation of film was affected by the condition of the wall. In a study bearing on wall films Fowkes and Harkins $(6,11)$ determined values of surface pressure at solid-liquid interfaces presenting data for a number of aqueous systems observing that the films are gaseous at low pressure. It is believed that adsorption at the liquid-metal interface and possible creep of the alcohol molecules up the wall due to wetting of the wall by water resulted in more alcohol than was necessary to form monolayers at the gas-liquid interface. When one neglects any water creeping up the beaker walls, the total apparent water-interfacial area is $\mathbf{2 . 9 5}$ times the water-air interface. The amount of alcohol and water creeping up the walls of the beaker may well depend on the concentration and nature of the alcohol. The wall appeared to be dry.

In the case of cetyl alcohol a noticeable reduction in evaporation rate is achieved with the lowest amount added in this study, $0.00025 \mathrm{~g}$. With stearyl alcohol a much higher amount is required, 0.0006 g., for a commensurate effect. With $0.0005 \mathrm{~g}$. cetyl alcohol a large and possible useful retardation is obtained. At low concentrations, $0.001 \mathrm{~g}$. in our apparatus, cetyl alcohol is the most effective of the alcohols considered, while stearyl alcohol is more effective at $0.020 \mathrm{~g}$. By contrast $1.1 \mathrm{~g}$. dodecyl alcohol has the same effect as $0.00025 \mathrm{~g}$. of cetyl alcohol.

This investigation shows that resis- tance values of $R_{i}$ of the order of 10 sq. ft. hr. atm. (lb. mole) $)^{-1}$ are obtained for effective retardants which are of the same order found by Mysels; by Langmuir and Langmuir for water into flowing air; and by Mansfield; by Rosano and La Mer; and by Archer and La Mer as well as McArthur and Durham for the evaporation of water into still air. This leads one to suspect that this is the maximum to be achieved with monomolecular films in both engineering and laboratory operations with water at atmospheric pressures.

Values twentyfold higher are obtained by Langmuir and Langmuir for the evaporation of ethyl ether from water through various films with both stagnant and flowing air. The higher resistance may well be due to the film giving a higher diffusion resistance to the larger ethyl ether molecule.

In the vacuum work of Rideal where the rates are so much higher, 200 to 3,300 times the authors', the resistance required to reduce the evaporation to one half, as observed, will be $1 / 200$ to $1 / 3,300$ that of the authors'. It is difficult to see why the presence of the vacuum or high rates should alter the film resistance unless the interface is agitated by a phemomenon related to boiling.

\section{CONCLUSIONS}

The magnitude of gas-liquid interfacial resistances under controlled conditions has been measured over wide concentration ranges with four alcohols yielding quite different results. From the partial data available in the literature interfacial resistances in the work of others have been estimated and compared with those of the present study. This should allow a prediction of the order of magnitude of such effects in a number of practical situations.

\section{ACKNOWLEDGMENT}

The assistance of the Faculty Research Fund of the Horace H. Rackham School of Graduate Studies of The University of Michigan with a grant which was used in part for the equipment and preliminary work of this study is acknowledged with appreciation.

\section{NOTATION}

$K_{O G}=$ pseudo mass transfer coefficient, lb. mole/(hr.) (sq. ft.) (atm.)

$k_{f}=1 / R_{i}=$ film mass transfer coefficient, lb. mole/(hr.) (sq. ft.) (atm.)

$k_{G} \quad=$ gas-phase mass transfer coefficient (determined with no alcohol present), lb. mole/(hr.) (sq. ft.) (atm.)
$R_{i}=1 / k_{f}=$ interfacial film resistance, (hr.)(sq.ft.)(atm.)/lb. mole

\section{LITERATURE CITED}

1. Adam, J., "Physics and Chemistry of Surfaces," 3 ed., p. 25, Oxford Univ. Press, Oxford, England (1941).

2. Archer, R. J., and V. K. La Mer, J. Am. Chem. Soc., 59, 200 (1955).

3. Baranaev, M., J. Phys. Chem. (U.S.S.R.), 9, 69 (1937), as reported in Chem. Abstr., 31, 4190 (1937).

4. Docking, A. R., E. Heymann, L. F. Kerley, and K. N. Mortensen, Nature, 146, 265 (1940).

5. Dressler, R. G., and A. G. Johanson, Chem. Eng. Progr., 54, 66 (1958).

6. Fowkes, F. M., and W. D. Harkins, $J$. Am. Chem. Soc., 62, 3377 (1940).

7. Glazov, N. I., J. Phys. Chem. (U.S.S.R.), 13, 840 (1939), as reported in Chem. Abstr., 34, 7697 (1940).

8. Ibid., 1642 (1939), as reported in Chem. Abstr., 35, 17 (1941).

9. Groth, K., "Second International Congress of Surface Activity," Vol. I, p. 275, Butterworths, London (1957).

10. Grundy, F., ibid., p. 270.

11. Harkins, W. D., and F. M. Fowkes, J. Am. Chem. Soc., 60, 1511 (1938).

12. Hedestrand, Gunnar, J. Phys. Chem., 28, 1245 (1924).

13. Langmuir, Irving, and D. B. Langmuir, ibid., 31, 1719 (1927).

14. Langmuir, Irving, and V. J. Schaefer, J. Franklin Inst., 235, 119 (1943).

15. Mansfield, W. W., Nature, 172, 1101 (1953).

16. Ibid., 175, 247 (1955).

17. MeArthur, I. K. H., and K. Durham, "Second International Congress of Surface Activity," vol. I, p. 262, Butterworths, London (1957).

18. Milbauer, Zdenek, Listy Cukrovar, 56, 421 (1938), as reported in Chem. Abstr. 32, 8816 (1938).

19. Moulton, K. B., Weather, 12, 223 (July 1957).

20. Mysels, K. J., Science, 129, 38 (1959).

21. Powell, R. W., Trans. Faraday Soc., 39, 311 (1943).

22. Proceedings of the First International Conference on Reservoir Evaporation Control, Southwest Research Institute, San Antonio, Texas (1956).

23. Rideal, E. K., J. Phys. Chem., 29, 1585 (1925).

24. Rosano, H. L., and V. K. La Mer, J. Am. Chem. Soc., 60, 348 (1950).

25. Sebba, F., and H. V. A. Briscoe, $J$. Chem. Soc., 106 (1940).

26. Ibid., 128 (1940).

27. Sebba, F., and N. Sutin, ibid., 2513 (1952).

28. Sklyarenko, S. I., and M. K. Baranaev, J. Phys. Chem. (U.S.S.R.), 12, 271 (1938), as reported in Chem. Abstr., 33 4846 (1939).

29. Ibid., 14, 839 (1940), as reported in Chem. Abstr., 36, 4002 (1942).

30. - and K. I. Mezhueva, ibid., 18, 447 (1944), as reported in Chem. Abstr., 39, 2919 (1945).

31. Sternling, C. V., and L. E. Scriven, A.I.Ch.E. Journal, 5, No.4, 514 (1959).

Manuscript received August 9, 1958; revision received March so, 1959; paper accepted A pril 3, 1959 Paper presented at A.I.Ch.E. Atlantic City meeting 